Mens

revue d'histoire intellectuelle de l'Amérique française

\title{
Rony Blum. Ghost Brothers. Adoption of a French Tribe by \\ Bereaved Native America. Montréal et Kingston, McGill-Queen's University Press, 2005. 464 p.
}

\section{Guillaume Teasdale}

Volume 8, numéro 1, automne 2007

URI : https://id.erudit.org/iderudit/1023155ar

DOI : https://doi.org/10.7202/1023155ar

Aller au sommaire du numéro

Éditeur(s)

Centre de recherche en civilisation canadienne-française

ISSN

1492-8647 (imprimé)

1927-9299 (numérique)

Découvrir la revue

Citer ce compte rendu

Teasdale, G. (2007). Compte rendu de [Rony Blum. Ghost Brothers. Adoption of a French Tribe by Bereaved Native America. Montréal et Kingston, McGill-Queen's University Press, 2005. 464 p.] Mens, 8(1), 152-156.

https://doi.org/10.7202/1023155ar d'utilisation que vous pouvez consulter en ligne.

https://apropos.erudit.org/fr/usagers/politique-dutilisation/ 


\section{Rony Blum. Ghost Brothers. Adoption of a French Tribe by Bereaved Native America. Montréal et Kingston, McGill-Queen's University Press, 2005. $464 \mathrm{p}$.}

Avec Ghost Brothers, l'historienne Rony Blum présente une version revue et augmentée de sa thèse de doctorat soutenue à l'Université hébraïque de Jérusalem en 2000. Comme le sous-titre du livre le laisse entendre, l'auteure suggère une approche "inversée » de l'établissement de colons français en Amérique du Nord durant l'époque coloniale, plus précisément dans la vallée laurentienne entre 1608 et 1663. En effet, Blum propose de voir le peuplement de la NouvelleFrance à «l'époque glorieuse » non pas comme un mouvement de francisation des Amérindiens mais de nativisation des Français. Ce processus aurait été si important qu'il serait plus approprié de parler d'assimilation des Français au monde amérindien que d'accommodation mutuelle entre premiers peuples et nouveaux venus. Par surcroit, la nativisation prononcée des premiers colons en Nouvelle-France est peut-être ce qui a sauvé cette fragile entreprise coloniale et permis à celle-ci de perdurer jusqu'en 1663, moment de la réelle prise en charge par la Couronne française de la destinée de sa colonie nord-américaine. Présentant donc sous un angle essentiellement culturel l'étude de la présence précoce de Français dans la vallée du Saint-Laurent, Blum répartit son ouvrage en huit chapitres.

Dans le chapitre premier, Blum démontre la faiblesse et l'instabilité de la jeune colonie en s'attardant sur quatre événements importants survenus avant 1663 :1) la prise de Québec par les frères Kirke en 1629, 2) la destruction de la puissante confédération huronne en 1648, 3) la Fronde à $\mathrm{Pa}$ ris au cours de cette même année, révolte qui allait bien sûr jeter encore plus d'ombrage sur les efforts coloniaux d'outre- 
mer, et 4) la bataille de Long-Sault en 1661. Alors que les Hurons et les différents peuples algonquiens de la vallée laurentienne étaient déjà affaiblis en raison de nombreux et dévastateurs raids iroquois, les colons français ont néanmoins grandement eu besoin d'eux pour assurer leur subsistance. Dans plusieurs cas, cela signifia ni plus ni moins vivre parmi ces groupes et adopter leur mode de vie. Dans le second chapitre, l'auteure illustre de quelle façon les colons français appréciaient au quotidien leur liberté d'action et trouvaient beaucoup d'avantages au mode de vie amérindien. Au XVII siècle, l'effort missionnaire en Nouvelle-France ne rapportait que de maigres résultats et il semble que la soi-disant stratégie visant à concentrer les efforts sur les enfants amérindiens fut loin d'être gratifiante : "Yet while very few Native children became Frenchified, all the immigrant children acquired various degrees of Nativization " (p. 71). Par la suite, dans le troisième chapitre, l'auteure compare les périodes pré- et post1663 pour démontrer en quoi il serait abusif de parler d'accommodation mutuelle durant les premières décennies de colonisation. Alors que l'historien américain Richard White décrivait dans son livre The Middle Ground (Cambridge, 1991) les relations franco-amérindiennes dans les Grands Lacs entre 1650 et 1820 comme un processus perpétuel d'accommodation, Blum est pour sa part catégorique concernant la vallée du Saint-Laurent avant 1663 : les Français s'assimilaient volontairement. Une fois sa perception des débuts de la Nouvelle-France explicitée, Blum s'emploie dans les chapitres subséquents à soutenir davantage sa thèse par l'analyse de cas témoignant d'une transformation prononcée des mœurs et coutumes des colons.

Les effets dévastateurs de l'alcool chez les Amérindiens sont souvent évoqués, et cela dès les premières décennies d'échanges interculturels. Blum rappelle cependant qu'il ne 
faudrait pas passer sous silence le fait que nombre de colons développèrent quant à eux une dépendance au tabac. Selon les missionnaires de l'époque - et à leur grand désarroi ! - il s'agissait d'un exemple concret de la nativisation des colons : "While alcohol undermined the traditional life of Aboriginal nations, the French Canadian clergy saw French smoking as a sign of Nativization [...] » (p. 98). En effet, cette nouvelle pratique favorisait l'intégration des nouveaux arrivants au monde amérindien car fumer encourageait la fraternisation. Par ailleurs, la fréquentation quotidienne d'Amérindiens a eu pour impact la redéfinition de la masculinité chez les colons : "Yet there were many more new types in the New World, which indicated a new kind of masculinity. Both habitants and coureurs de bois were new male models and shared a new-found pride » (p. 104). Coupés de leurs points de référence d'outre-mer et encerclés de peuples amérindiens, les colons étaient désormais exposés à de nouvelles influences. Dans la même foulée, le faible nombre de femmes françaises présentes dans la colonie avant 1663 a favorisé un métissage entre Français et Amérindiennes qui allait bien au-delà de l'aspect physiologique. L'univers culturel tout entier de ces Français fut bouleversé. Par exemple, ils durent apprendre en quoi le rôle des femmes dans les sociétés amérindiennes était différent, apprentissage qu'ils firent tout en reconsidérant ce qu'était pour eux la masculinité. Le fait d'entretenir une relation intime avec une Amérindienne signifiait aussi une plus grande intégration au monde amérindien. Bref, dans un contexte où la plupart des nouveaux arrivants vivaient une période de grande instabilité, chacun dut redéfinir sa personne et son environnement social : «The perception of a nebulous and developing inside and outside of society, resulting from an inclusive, yet evolving, socio-cultural porosity and interdependence, was being engaged by an internal 
multivalence within the individual» (p. 235). Et pour plusieurs cette quête de sens se traduisit par leur nativisation, transformation qui devint même une source de fierté.

Blum porte un regard quelque peu novateur sur les relations entre Français et Amérindiens dans la vallée du SaintLaurent au XVII ${ }^{e}$ siècle. De toute évidence, elle n'est pas indisposée par l'idée de toucher de plein fouet certaines sensibilités historiques, notamment " l'indianisation » des habitants de la Nouvelle-France. En s'accordant cette liberté intellectuelle, Blum relativise du coup les succès du projet de «francisation" des premiers peuples. La "canadianisation» ou la « nativisation » des colons français dans la vallée laurentienne débuta très tôt et, hormis les missionnaires et quelques membres de l'élite, aucun n'y voyait problème. Dans les circonstances, il serait simpliste de se limiter aux emprunts matériels pour comprendre les changements culturels des Français de la vallée du Saint-Laurent au XVII ${ }^{\mathrm{e}}$ siècle, et Blum est à cet égard fort convaincante.

L'approche « inversée » préconisée par l'historienne nous oblige également à voir l'installation de colons français dans la vallée du Saint-Laurent entre 1608 et 1663 comme l'immigration de Blancs chez les Amérindiens. En effet, tout au long de son ouvrage, Blum ramène en avant-plan la facette migratoire de cette expérience coloniale. D'ordinaire, une migration entraîne de nombreux changements culturels chez les migrants, pour ne pas parler de chocs culturels. En général, les nouveaux arrivants s'adaptent à leur société d'accueil beaucoup plus qu'ils ne l'influencent, surtout lorsqu'ils ne sont qu'une poignée d'individus, célibataires et majoritairement de sexe masculin. Certes, les colons ont construit des habitations regroupées en villages, mais leur proximité avec les Amérindiens ne faisait aucun doute et Blum le démontre sans équivoque ; ces Français ont été acceptés au sein du monde 
amérindien. Les études migratoires (Migration Studies) représentent un champ historique qui demeure peu exploité - et cela est d'autant plus vrai en ce qui concerne la période coloniale - alors, en ce sens, la contribution de Blum est notable.

La réflexion de l'historienne, qui accorde une place importante à la multidisciplinarité, est soutenue par l'utilisation d'une quantité impressionnante de sources primaires, françaises et anglaises. Notons à cet effet qu'à la différence de plusieurs chercheurs anglophones s'intéressant à l'histoire de l'Amérique française, Blum n'est aucunement limitée par certaines subtilités de la langue française. Ghost Brothers constitue donc un ouvrage fort intéressant qui, espérons-le, ne restera pas sans écho chez les historiens francophones.

Guillaume Teasdale

Département d'bistoire Université York 